\title{
4. Selling Authenticity: The Aesthetics of Design Boutiques in Montreal
}

\author{
Guillaume Sirois
}

\begin{abstract}
This chapter considers how the practice of design takes place in a city like Montreal, where it has been widely promoted in the last decade. It focuses on designers who create everyday-life objects and, more specifically, on the visual environment that characterises the design boutiques in Montreal's Mile End district. It shows that the aesthetics of these spaces are developed around a set of values, namely authenticity, materiality and hospitality. These aesthetics are crucial to distinguish design products and signal to potential clients that these products belong to an alternative version of the market economy. Yet, the aesthetics of these boutiques contribute to an aesthetics of gentrification, which raise questions about the local culture, the history of the neighbourhood, and its population.
\end{abstract}

Keywords: Designer; Boutique; Visual Culture; Montreal; Creative City

In Montreal, the practice of design has been actively supported by city officials in the last decade. Indeed, in 2006, the city obtained the international designation of UNESCO City of Design, and, at the same occasion, inaugurated a new office charged with the mandate of promoting the various practices of design in the city. If the designation came as a surprise for many observers of cultural development in the city, it must be acknowledged, more than ten years later, that this creative activity has progressed significantly in the city. Among the various practices of design that have flourished in Montreal since, this chapter focuses specifically on the practice of designers who create objects (furniture, fashion accessories, household linen, toys, lamps, home decor, etc.). This specific practice of design has been widely promoted by the City of Montreal's Design Office in relation to tourism and 
economic development in an effort to make Montreal a design destination. More specifically, I consider here the stores specialized in local design that propose these objects to visitors and local clientele. Through visual methods, I have investigated the visual environment developed in the design boutiques in the Mile End district in Montreal, a neighbourhood that went through significant waves of gentrification over the last decades. My analysis shows that the aesthetics developed in these boutiques are centred around a set of values, namely authenticity, materiality, and hospitality. These visual environments are meant to distinguish design products from more banal commodities that can be found in any shop and thus signal to lovers of design that they will find in these boutiques products that correspond to their values and lifestyle.

The first section of the chapter gives contextual details by briefly examining how design has become a key area of cultural policy intervention in Montreal, as it was perceived as a strategic industry that is capable of giving a public face to the re-imagined creative identity of the city. The second section turns to object designers themselves to consider how their practice takes place in the city. Finally, the third section provides a visual analysis of a series of boutiques visited during this investigation. It looks closely at their visual environment to show how it is aligned with the taste of the community of "creative" people who have recently nested in the neighbourhood.

\section{Showcasing Montreal's Creativity}

In the last two decades, the cultural landscape in Montreal has been significantly transformed by two interrelated policy streams: the first one aims at transforming the city into "a cultural metropolis of the twentyfirst century" (Brunet and Kadri 2014), whereas the second one seeks to have Montreal internationally recognized as a "city of design." The policy conversation on these topics dates back to 2002, when Gérald Tremblay, the newly-elected mayor of Montreal, invited leaders from various sectors to convene in the "Sommet de Montréal" to reimagine the development of their city. This is around the same period that a group of cultural leaders created the advocacy organization Culture Montréal, a group dedicated to the promotion of a new place for arts and culture in the developing city. This group of cultural leaders enthusiastically embraced the paradigm of the new cultural economy that was emerging at the time around the world (Hewison 2014), in which arts and culture are conceived as key development tools 
to reinvigorate city centres affected by successive waves of the relocation of manufacturing facilities overseas. Fuelled by a popular and academic discourse on notions such as "creative economy" (Throsby 2010), the model of the "creative city" was largely perceived as an easy-to-import model of development. Following this model adopted by cities around the world, like Barcelona (Degen and Garcia 2012), which always served as a strong example in Montreal (Cohendet, Grandadam and Simon 2011), the city started to count on culture and creativity as a key sector to spearhead its economic and urban redeployment.

The work of Richard Florida was particularly influential in the development of such a vision in Montreal (Tremblay and Tremblay 2010). Even if Florida's work has been seriously criticized from an academic perspective (Peck 2005), his views were highly regarded by city officials. Indeed, the American scholar was invited to the city by Culture Montréal to study its potential for creativity growth. His analysis (Stolarick, Florida, and Musante 2005) concluded that the city has significant assets that can be used to attract creative people, which are said to be an essential element of economic and urban development. The campaign led by Culture Montréal was rapidly successful and convinced city officials to adopt, in 2005, a first cultural policy bearing the title "Montreal, Cultural Metropolis." Yet, ambitions associated with this vision were beyond the capacity of the municipal administration, and Culture Montréal's advocacy efforts also targeted the two other levels of government (provincial and federal) as well as the business sector. These efforts led to another summit dedicated specifically to the cultural metropolis project, which saw all partners agreeing on a ten-year action plan to transform such a vision into reality. Overseen by a steering committee of high officials, the plan has had several versions over the years. Among the things that remain constant in these policy documents is the insistence on positioning the city on the international stage. Here, the influence of Florida is patent as several documents insist on the necessity to compete with the "world's major cities" or compare Montreal with major cultural capitals like Paris, New York, or Berlin.

Since the adoption of the first policy, it was clear for the proponents of the cultural metropolis vision that such a project must be translated into physical changes in the city. In this perspective, the practice of design appeared as the perfect creative discipline by which these changes could be brought about, since this practice is multi-faceted and manifests itself in various forms in the city. Indeed, in its definition of design, the city of Montreal adopts a very broad perspective: "For the City of Montreal, design is an activity of ideation, creation, planning, production and management 
that influences the quality of its living environment, makes its economy more competitive, participates in its cultural expression and strengthens its identity and that of its businesses" (Ville de Montréal 2006). With such a definition, the city of Montreal has promoted various practices of design in the last decades, from the conception of new public spaces to the presentation of ephemeral installations throughout the city or the promotion of objects designed in Montreal. The declared ambition of municipal authorities is to turn the city into a "world-class design centre," so that all citizens and visitors of the city will understand, at first glance, that they are in a creative environment.

Among the many initiatives put in place by the City of Montreal's Design Office to promote local design, there is the CODE souvenir catalogue, a promotional tool targeting private and public corporate buyers, as well as the general public. The catalogue, produced annually, presents a selection of the best products created by local designers that can serve as corporate presents or souvenirs from Montreal. With this initiative, the city hopes to link business development and the advancement of the creative identity of Montreal by increasing local purchases. Thus, the City of Montreal transforms commercial transactions into a culturally significant activity. Today, shopping is a ritualistic activity (Miller 1998) that has important significance in contemporary societies. Indeed, Sharon Zukin (2004) argues that shopping is no longer merely a necessary activity by which we acquire the things that we need, but also a mode of expression in public. Therefore, she maintains that shopping is a creative activity, especially when it comes to fashion and lifestyle, since it bears the promise of an improved self and reveals our aspirations about ourselves and our society. However, this is also one of our most controlled activities, since all our purchasing patterns are carefully scrutinized by marketers, stores, and advertisers in the hope of managing it in a more refined way.

\section{Designers in the City}

Contemporary designers are caught in a strange paradox. On the one hand, their discipline has been historically understood as a form of resistance to the industrialization and standardization of life that comes with a capitalist economy. A Victorian creator like William Morris, who is often regarded as a founding figure of modern design, conceived his work as a way to value human craftmanship in contrast to the limited possibilities offered 
by industrial production (Midal 2009). According to this vision, the role of the designer is to make beauty accessible to people through the objects and environment that surrounds us every day. This initial vision is carried forward by social designers who consider that their main task is to improve life in society not only by bringing beauty, but also innovative solutions, to social, environmental, and technological problems (Tromp and Hekkert 2019). On the other hand, design has always been deeply embedded in a capitalist economy as designers create goods intended to be produced and distributed on the market. They conceive beautiful objects that are purposely created to arouse our desire and increase consumption.

In this perspective, designers are now key players in what Gilles Lipovetsky and Jean Serroy (2013) call the "aesthetization of the world." With this term, the two authors do not mean that we now live in a world of absolute beauty, but rather that we have entered a new state of the capitalist economy - that they call "artistic capitalism" - in which aesthetics have become a structural factor. If questions related to aesthtetics were generally minor or peripheral in the market economy, it is now a key strategy by which entrepreneurs distinguish their products from the competition. Instead of competiting on the price of their commodities as is traditionally the case in the market economy, entrepreneurs pay greater attention to the stylization of their products and the environment in which they are presented. This way, their products acquire, through aesthetic means, a certain signification and are associated with a specific way of life that correspond to the desire of their customers. In this perspective, the design sector nowadays takes place in a "cool capitalism" (McGuigan 2009) that tends to absorb any kind of criticism towards capitalism and turns it into a competitive asset.

In a first phase of research, I conducted a series of ten interviews with Montreal designers who conceive various kinds of objects to understand how contemporary practitioners situate themselves vis-à-vis this tension. The statements collected during this series of interviews are used here only as an illustration of local designers' discourse, as a fully-developed analysis of this discourse has been presented elsewhere (Sirois 2020). In fact, Montreal designers see themselves and their production as an incarnation of an alternative capitalist economy. Indeed, the respondents were unanimously comfortable with conducting their professional activity within the capitalist economy: they are generally at ease with calling themselves entrepreneurs, and many of them embrace this designation with enthusiasm. Several of the respondents even fully assume that their production takes place in the luxury industry and that 
their merchandise is accessible only to economically-privileged people. However, they also insist on a series of alternative values guiding the development of their practice, which they specifically oppose to the current state of manufacturing production in the globalized capitalist economy. Creativity is, of course, one of the first values that is praised by designers, as their productions display originality by contrast to the repetitiveness of mass production. Similarly, many designers insist on the sustainability of their production, since their objects are made to last, which is contrary to the "fast fashion" movement that produces goods made to be consumed and discarded rapidly. Finally, their mode of production is also an area where they distinguish themselves from mass production: many of them make a point of producing locally, slowly, and in an inspiring environment, away from the stressful and dehumanized production of big industries.

In such a context, the question becomes how is this production distinguished from more banal commodities when it is presented to the public? How is this specific production marketed to signal its difference? The city of Montreal has deployed significant efforts over the last decade to promote these objects that embody or express the creative identity of the City. Does it become clear to strollers who walk its streets? As it has been suggested (Remaury 2006), recognizing a production as "being design" is a marker of taste that singles out these objects as belonging to a certain aesthetic category. So, what are the specific markers that distinguish these objects?

To study these questions, I established a database of designers working in Montreal, based on the repertoire of designers assembled by the city's Design Office. The database concentrated solely on designers who conceive objects (furniture, accessories, objects for domestic and professional spaces, etc.), excluding those who specialize in designing environments, experiences, events, or creations that are not for sale in design shops. For each of the designers included in the database, I also tracked the main points of purchase where their products are available. Thus, I obtained a list of boutiques and shops where local design is offered in the city. All these points of purchase were put on a map and categorized by the number of local designers represented at the location.

The greatest concentration of boutiques specialized in local design is found in the Mile End, a neighbourhood comprised in the borough of Plateau-Mont-Royal, just North-East of Downtown. From a small village of artisans and workers that it was in the $19^{\text {th }}$ century, the area quickly evolved to become an important industrial sector in the city. At the beginning of the 
twentieth century, the city actively courted major companies in the garment industry, which resulted in building the new John W. Peck manufacturing plant at the corner of Saint-Laurent boulevard and Saint-Viateur street. From 1920 to 1990, Montreal was the country's capital of the garment industry (Desjardins 2017) and a great concentration of these factories were situated in the east part of the neighbourhood, surrounded by modest habitations for the workers. In addition, the neighbourhood has traditionally been home to several migrant communities that occupy a special place in the city's identity, notably the long-established Jewish, Portuguese, and Greek communities.

However, with the decline of the manufacturing production in the sector, the neighbourhood has undergone significant transformations in recent decades. The Peck manufacturing plant is now occupied by the French videogame multinational Ubisoft, and the neighbourhood is among the most expansive sectors in terms of real estate. Following a typical narrative involving creative activity in the gentrification process (Vivant and Charmes 2008), the neighbourhood has been transformed by new creative activities that have taken the place of former factories, which were emptied out by delocalization movements. In addition to the videogame industry that has florished in the sector, attracted by generous tax benefits offered by the state, the Mile End is today well-known for its independent music scene (Straw 2018) that attracts young musicians from across the country and beyond. Non-profit organizations and artists' collectives have also settled in former industrial buildings, and some of them are now engaged in a social struggle to preserve the authenticity and affordability of the neighbourhood (Douay 2012). As it is common in this type of transformation (Maltais 2016), the commercial landscape in the neighbourhood has adapted to the new population that now lives and works in the neighbourhood: new restaurants, bars, and shops now operate next to shops that have been in this neighbourhood for decades.

Among these new ventures that now populate the main shopping streets are the design boutiques. I have identified a total 22 different points of purchase that offer the products of local designers in this neighbourhood. The concentration of boutiques is particularly notable along the SaintLaurent boulevard, which occupies a distinctive place in Montreal. The street that Montrealers call the Main officially divides the city between the East and the West and, unofficially, between the francophone and anglophone communities (Germain and Rose 2000). It is along this street, which functions as a symbol of the city's diversity and heterogeneity (Poulot 2017), that many design boutiques were established, adding a new layer of 
cultural signification to the boulevard. Indeed, the physical presence of these boutiques along the street can be construed as the symbolic inscription of a new taste regime in the city landscape.

To better understand this phenomenon, all the boutiques in this neighbourhood were visited and 18 of them were systematically photographed following a pre-established shooting script (Suchar 1997). For each of them, a series of eight to ten photos was produced, including street view, shop windows, display furniture, and the merchandize itself. The following section presents the results of a content analysis (Rose 2016) that was carried out on the set of images.

\section{Visual Analysis: Displaying Design}

The first element that is striking when analyzing this visual material is the relative banality of these boutiques in the urban landscape. Indeed, at first glance, nothing seems to differentiate them from other restaurants and shops that populate the street. They generally occupy the first floor of a two- or three-storey building made of bricks or grey stone that is very typical in this sector. No visual element signals to visitors that they enter a district dedicated to design or fashion, as is the case in other cities. If some boutiques put a bench or a trestle in front of their shop windows, there is not much there to catch the attention of the average passer-by who is not looking out for design. This observation may seem surprising at first, but it is in fact the first marker of an aesthetic that is built around authenticity. As explained by Sarah Banet-Weiser, our contemporary society is now eager for anything that "feels authentic" as "we lament more and more that it is a world of inauthenticity, that we are governed by superficiality" (Banet-Weiser 2012:3). She argues that some of the cultural spaces that were once the territory of authenticity, notably self-identity and creativity, have been increasingly dominated by brand culture. In this perspective, the design boutiques are conceived as a space of resistance to the superficiality of the brand culture that is so prevalent in the design sector and retailing activity. By standing in opposition to global brands, local design boutiques strive to incarnate a form of authenticity that is made explicit in the visual aspect of the space. Such a preoccupation with authenticity leads to a great level of attention to the materiality of objects presented and the relation to customers, thanks to spaces that embody hospitality. 


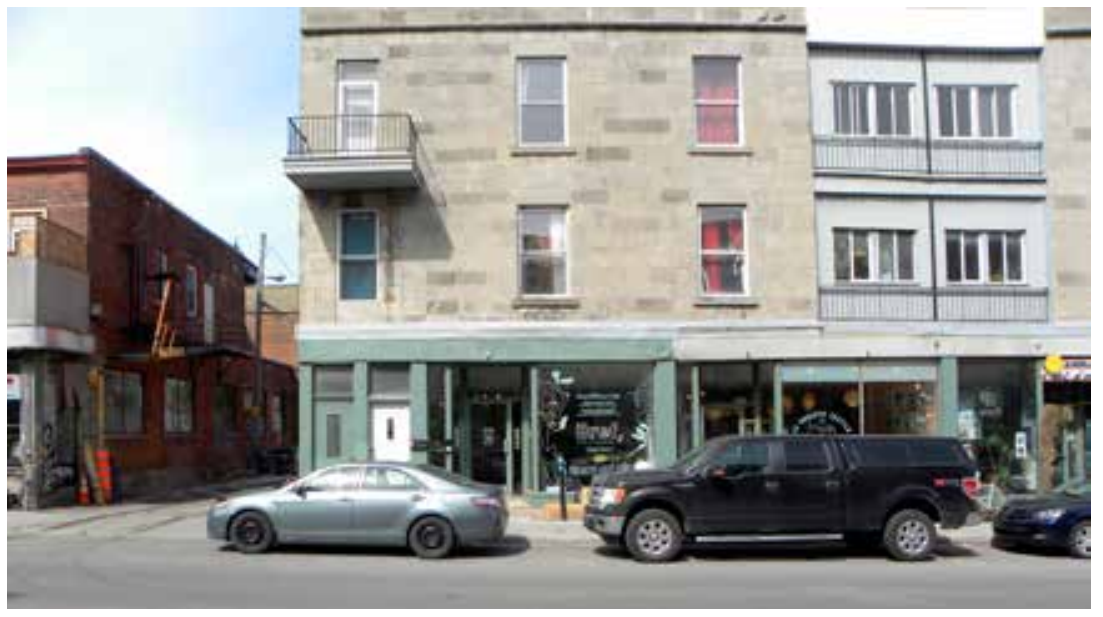

Figure 4.1: Bref, Montreal. Photograph by Pablo Saavedra-Renaud.

\section{Authenticity}

The notion of authenticity is ubiquitous in the discourse about local design, whether it is in the promotional discourse put forward by the City of Montreal or in the words of practitioners. Indeed, authenticity is conceived as a key value of this community as it differentiates their products from industrialization and mass production, artificial and composite materials, and the phenomena of delocalization of production. One of the first added-values of design is specifically to propose authentic goods, at least locally-conceived and preferably locally-produced, which demonstrate the creativity and originality of Montreal designers. This is, for example, what an experienced designer states when she is asked what would be her best advice to young designers: "You need to be authentic. This is the basis. To have your own universe, your own creativity. [...] It is unbelievable the number of young creators that come up with a product and it is only inspired by Pinterest, only copies. It is trendy. In order to last in this business, you need to find your own creation and it doesn't take only two months to find your style, your line." Such a value also has a strong presence in the commercialization of the objects produced by local designers. One of the boutiques studied here even has it in its logo. The boutique is called YUL Design in reference to the Montreal airport acronym, and the store's logo, which evokes a stamp, even states under the name of the boutique "certified authentic."

The preoccupation with authenticity is often conveyed by references to the past that populate the decor of these shops. It is suggested notably in a series of old objects put side by side with design products on the shelves of the boutiques. These objects may be a simple evocation of a somewhat idealized 


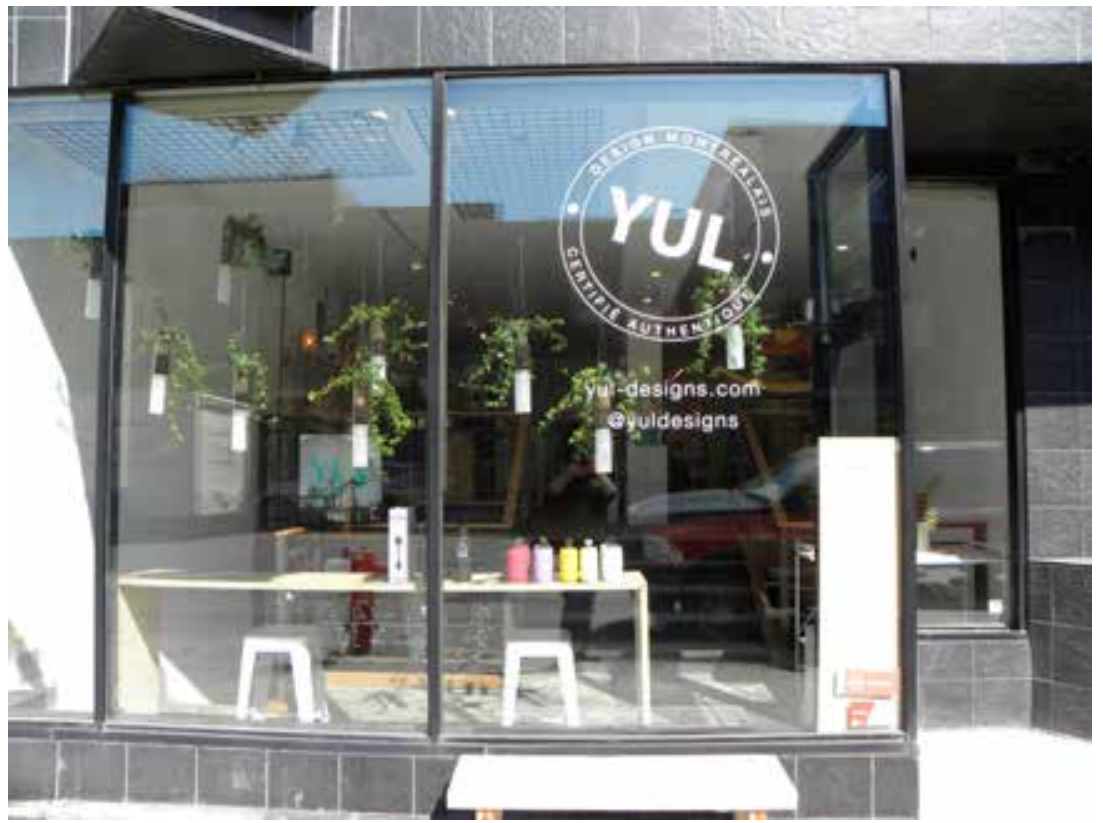

Figure 4.2: YUL Design, Montreal. Photograph by Pablo Saavedra-Renaud.

past, like the set of old objects (old encyclopedia, earth globe, and snowshoes) that is displayed in one boutique visited, or objects that are more closely related to craft culture, like the old sewing machine exhibited in other boutiques specialized in clothes or objects that evoke the local culinary culture, including a maple syrup cane, in the window of another boutique selling kitchen tools.

This evocation of the past also occurs in elements of furniture, like an old retail counter or antique display cases used to present the merchandise in other shops. The same designer who advises her young colleagues to value authenticity in their creative process also insists that such an authenticity should become obvious to customers who enter her boutique. She maintains that customers should immediately recognize that the environment is not cluttered with generic pieces of furniture but, rather, is carefully curated. The pervasive presence of the past in the design boutiques creates a link with the traditional commercial activity and allows the designer community to situate their production in line with an imagined glorious past predating globalization and the neoliberal economy. Even though the modest population that used to live in the neighbourhood would probably not have been able to afford these products, these boutiques are an attempt to recreate a romanticized urban life in which the city was inhabited by small artisans making durable goods and selling them to the local community. 


\section{Materiality}

The desire to show authenticity is also carried in the great emphasis that is put on the materiality of the objects presented. Although there are rare exceptions, the display of the merchandise in these boutiques is generally characterized by a certain minimalism so that the customer can appreciate the physical quality of the object. Accent is put on the pairing of colours, on the contrast between different materials, or on the singular shape or texture of an object. For designers who consider that all of these elements are integral parts of their creations, this aspect is paramount. For instance, one designer specializing in ceramics comments: "It is the material that informs me about its potential and it is with this information that I can make a good design." And this relation to the material extends beyond the creation of the object itself to its marketization. She adds: "When I am looking at an object, when I am drawing, creating, conceptualizing, I am thinking about the packaging. I have not done anything yet, and I am already thinking about the packaging. It is a whole."

To highlight this key dimension in the design process, most of the boutiques studied here do not balk at using, in their own visual environment, rich materials associated with quality and durability. Wood, leather, cork, fabrics like linen and felt, or marble are common materials found in these shops. This attention to materiality is even visible in labelling, posters, and display panels that populate the decor of these boutiques, which are themselves made of wood, rich papers, and blackboards, often with a touch of originality. This is another way to affirm the importance of materiality and craft culture and therefore signal to customers the values promoted in these commercial settings.

More than just for vanity, these aesthetic choices reflect a vision of craftmanship and excellence. Indeed, the quality of the material and the mastery of execution in the fabrication of an object are commonly presented as one of the central justifications for the high price of these commodities. One designer specialized in high-quality furniture explained how he presents his products to his clients: "It is made in Montreal. It is a product that is made to last. We can guarantee the product. All that has a value." For him, "it is an education that needs to be done towards the clientele to make them understand that they invest in something, that this is not only a short-term purchase." Such a statement is representative of an often-repeated discourse in the designer community according to which customers get value for their money when they buy design products because they acquire goods that are made to last, as they are fabricated with rich materials and made locally by 


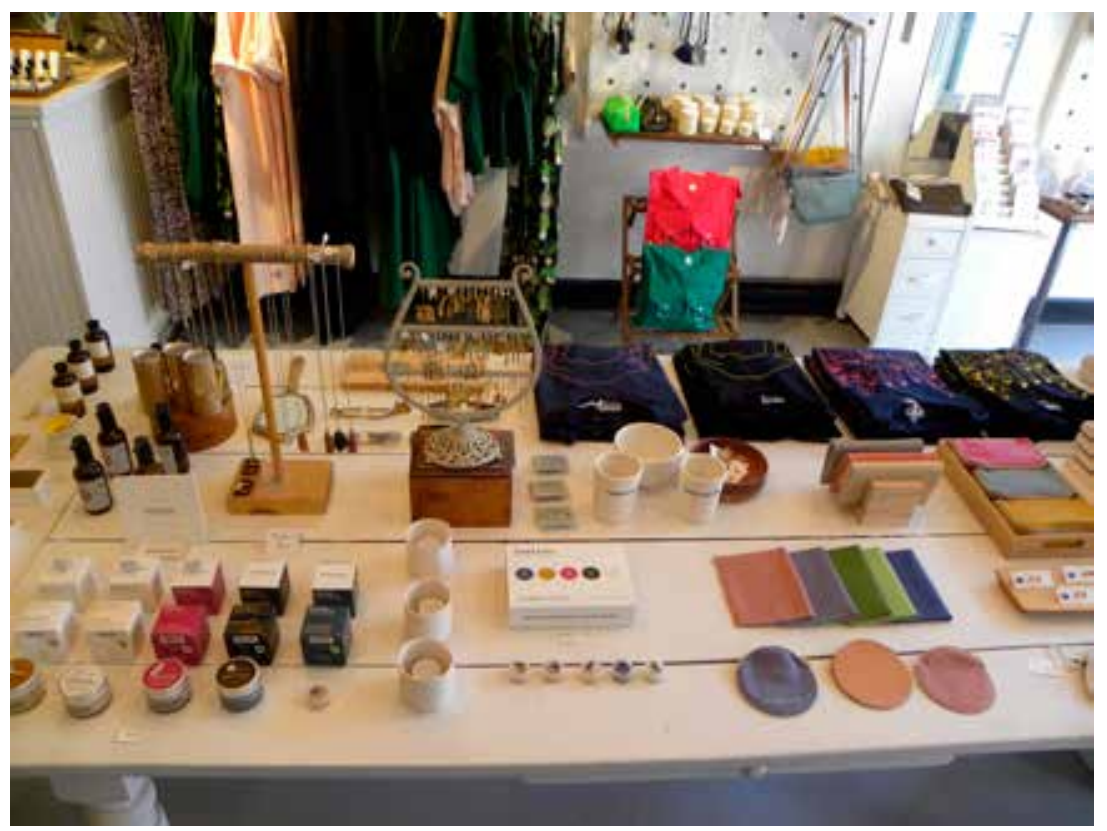

Figure 4.3: General 54, Montreal. Photograph by Pablo Saavedra-Renaud.

artisans who have developed an advanced expertise in this material and the process of fabricating high-quality goods. Moreover, such a discourse holds that this mode of production is more ethical as it is not based on the overexploitation of workers, and more sustainable as it opposes the overconsumption entailed by low-quality production.

\section{Hospitality}

Finally, a last point to note about these commercial spaces are the efforts deployed to make them welcoming and warm. For example, one of the boutiques specialized in kitchen tools includes in its space a couch, so that the clientele can take a moment during their shopping to think about the choice they have to make or simply sit down and relax to enjoy the good smell coming out of the kitchen situated at the back of the shop. Along the same lines, two other boutiques studied here are actually hybrid spaces, as they integrate both a coffee shop and a boutique, where the customer can sit down for a coffee or a drink while looking at, and eventually buying, objects designed by local creators. These strategies can be construed as an effort to transform these commercial spaces into living spaces that would 


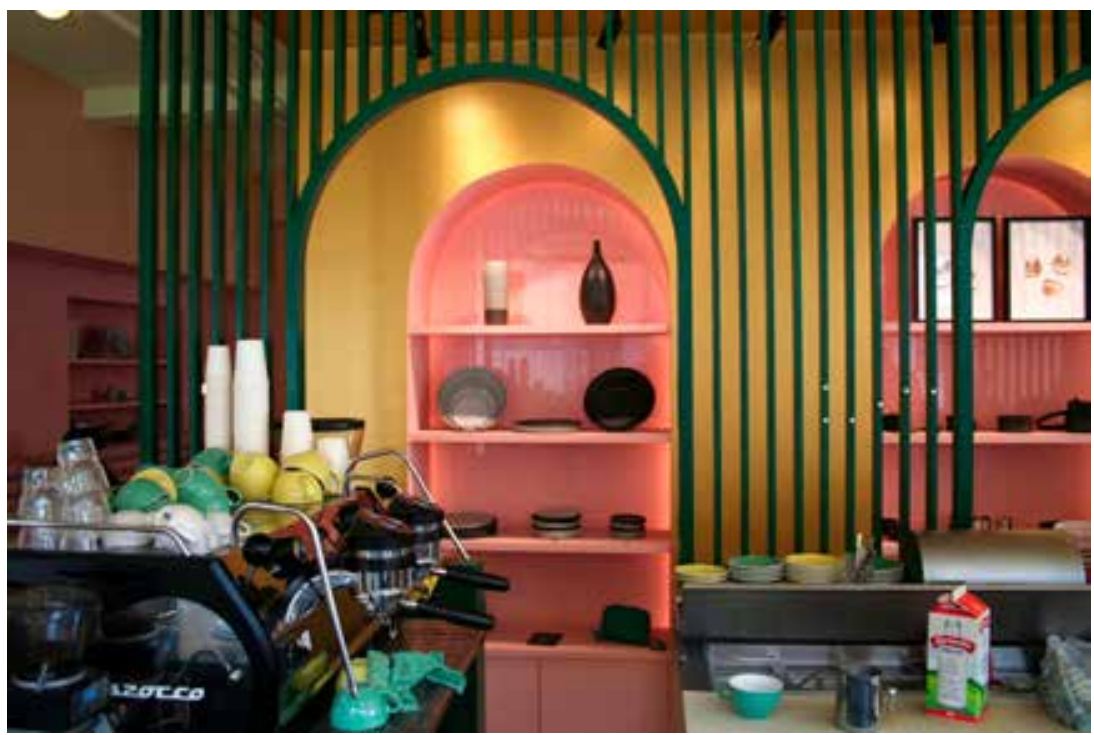

Figure 4.4: Pastel Rital, Montreal. Photograph by Pablo Saavedra-Renaud.

be friendlier to customers. In a more discreet way, this is the same strategy that is used by many shop owners who add plants, elements of furniture, and images on the wall that are not for sale but rather aimed at creating a "homey" atmosphere. One of the designers clearly explained to me that the guiding principle in the design of his boutique was to make it look like an apartment. A comparable strategy is to organize cultural events in the boutiques on the occasion of the launch of a new collection or simply to highlight the work of a creator. Like a gallery opening or book launch, these events transform the boutique into a social space in which the well-informed public gathers, creating visibility for the boutique.

All these hospitality strategies certainly have a commercial dimension. There is no doubt that setting up a convivial space and trying to expand the time spent by potential clients on location has always been one of the techniques of the good merchant. Yet, in the case of design boutiques, they seem to go one step further by trying to establish a long-term relationship with their clients and even to create a community around their commercial activity. This is especially important in the case of small businesses in which the promotional budget is very limited or even non-existent, and in a sector where most of the reputation is built on word-of-mouth referrals. This is where the work of the object designer meets that of the experience designer, as shopping for design is not only looking for the right object that answers one's needs, but also immersing oneself in a creative milieu. 
In this perspective, the preoccupation with conviviality is aligned with the discourse of several designers who insist on the importance of social relationships in the development of their work. Hence, they care for the experience of the customer and aim toward creating a space favouring authentic conversations and exchanges, away from the coldness and superficiality so prevalent in contemporary relationships, and especially in commercial relationships.

\section{Conclusion: In Search of Locality}

The City of Montreal has decided to invest in the promotion of its local designers because this creative industry was perceived as having the potential to show the uniqueness of the city. Such a belief is rooted in the discourse of this community of creators who claim to embody a form of authenticity, contrasting with the homogenization of lifestyle generated by the neoliberal economy. As noted by Sharon Zukin (2010), authenticity is nowadays an instrument of power, since the claim of being authentic in one's own taste generally corresponds to a claim of superiority. However, it remains very difficult to agree on what constitutes authenticity and it generally requires a step back to be able to see it. With Zukin, it can be argued that authenticity is made of various layers of cultural significance, which have settled in one place or one practice, whereas new people, new practices, or new venues only complicate such cultural significations. Thus, authenticity seems inseparable from the question of place, since it is always in relation to a certain local reality that authenticity can be recognized: this is the way things are in a specific place, not reproducing or importing cultural practices that are coming from elsewhere. Therefore, the authenticity of the Mile End district resides in its traditional working-class population and its industrial past that have so strongly coloured the development of the neighbourhood. However, the new population of creative people who live and work in the area has added a new layer of cultural signification that is now an integral part of the neighbourhood's identity.

One can ask what is typical of Montreal, or the Mile End, in these design boutiques that claim to represent the city's authentic creativity? There are, here and there, a few visual elements that evoke the local context, like a well-known photo of Montreal's airport in one boutique or an old advert that mentions the name of the city in another shop. However, these elements seem almost anecdotal; they are pieces in a general background but they are not particularly significant. Another element that might be 
more relevant is the presence of small advertisements disseminated in the decor of these boutiques that highlight local designers. However, this remains a minor practice as the local designer community prefers to stay away from brands, logos, and trademarks that are symbolically the opposite of the values - such as quality and durability - they want their product to represent. The designer community prefers to let the product speak for itself and the decor in which it is presented is there specifically to emphasize the qualities that an experienced customer will have no trouble recognizing.

The aesthetics that are developed in these boutiques have limited links to Montreal or to the neighbourhood in which they are established. The choices made with regards to the physical aspect of these commercial spaces emphasize a craft culture, of which one can undoubtedly find roots in the Mile End district. Yet, the revival of the craft culture is not unique to Montreal; it has surfaced in various forms in several cities throughout the world, including, for example, in New York, where it has been studied by Richard Ocejo (2017). As a consequence, the designer boutiques in Montreal look like many other shops in trendy neighbourhoods of other cities. Yet, the aesthetics of these boutiques, centred on authenticity, materiality, and hospitality, are important for local designers as those aesthetics signal to locals and tourists that the products they sell belong to the international movement that revisits the old savoir-faire of craft culture. These aesthetic choices are particularly important for a culture that rejects the usual marketing tools by which a product is distinguished from the competition. It is through these visual environments that they signify to potential clients that they will find on location products that are aligned with their values, which reflect their beliefs and lifestyle.

In their study of the "maker culture" in Portland, Oregon, Steve Marotta and Charles Heying (2018) show that the "local" is often conceived as a "defensive position" against globalization, which allows a community of practitioners to unite around a set of values, which includes authenticity, sustainability, and locality. Like in Portland, the community of local designers in Montreal share a set of values that is purposely opposed to the logic of neoliberal capitalism and globalization. The aesthetics they develop in the boutiques where they present their objects are not defined by a local cultural flavour, per se, or by a specific material that would be characteristic of Montreal or even a distinctive style, but rather are guided by this set of values. However, the inscription of such a version of locality in the urban landscape is certainly not neutral. In fact, the visual environment of these boutiques contributes to the elaboration of a specific aesthetics of gentrification that probably suits the lifestyle of the new creative population 
now living in the neighbourhood. Yet, the same visual enivronment also contributes to the structuring of the city around preferences in taste. In this context, one may wonder where that leaves many members of Montreal's community of local designers hoping that creating beautiful objects is also a way to enrich the lives of all their fellow citizens.

\section{Note}

All quotations from interviews are my own translation from the original in French.

\section{Works Cited}

Banet-Weiser, Sarah (2012) Authentic TM: The Politics of Ambivalence in Brand Culture. New York: New York University Press.

Brunet, Valérie and Boualem Kadri (2014) "La métropole culturelle: un nouveau visage de la triade mondialisation-métropolisation-mise en tourisme? Les cas de Marseille et de Montréal." In B. Kadri (ed.), Dynamiques métropolitaines et développement touristique. Montréal: Presses de l'Université du Québec, 37-6o.

Cohendet, Patrick, David Grandadam, and Laurent Simon (2011) "Rethinking Urban Creativity: Lessons from Barcelona and Montreal." City, Culture and Society 2.3: 151-158.

Degen, Monica and Marisol Garcia (2012) "The Transformation of the "Barcelona Model': An Analysis of Culture, Urban Regeneration and Governance." International Journal of Urban and Regional Research 36.5: 1022-1038.

Desjardins, Yves (2017) Histoire du Mile End. Québec: Septentrion.

Douay, Nicolas (2012) "Lactivisme urbain à Montréal: des luttes urbaines à la revendication d'une ville artistique, durable et collaborative." L'information géographique 76.3: 83-96.

Germain, Annick and Damaris Rose (2000) Montréal: the Quest for a Metropolis. New York: Wiley \& Sons.

Hewison, Robert (2014) Cultural Capital: The Rise and Fall of Creative Britain. London: Verso.

Lipovetsky, Gilles and Jean Serroy (2013) L'esthétisation du monde : Vivre à l'âge du capitalisme artiste. Paris: Gallimard.

Maltais, Alexandre (2016) "Anciens et nouveaux petits commerçants face à la transformation socioéconomique de deux anciens quartiers populaires montréalais.” Territoires urbains et mixité sociale 77: 148-165. 
Marotta, Steve and Charles Heying (2018) "Interrogating Localism: What does 'Made in Portland' Really Mean?" In Susan Luckman and Nicola Thomas (eds), Craft Economies. London: Bloomsbury, 141-149.

McGuigan, Jim (2009) Cool Capitalism. London: Pluto Press.

Midal, Alexandra (2009) Design: introduction à l'histoire d'une discipline. Paris: Pocket.

Miller, Daniel (1998) A Theory of Shopping. Ithaca: Cornell University Press.

Ocejo, Richard E. (2017) Masters of Craft: Old Jobs in the New Urban Economy. Princeton: Princeton University Press.

Peck, Jamie (2005) "Struggling with the Creative Class." International Journal of Urban and Regional Research 29.4: 740-770.

Poulot, Marie-Laure (2017) Le long de la Main cosmopolite : Promouvoir, vivre et marcher le boulevard Saint-Laurent à Montréal. Québec: Presses de l'Université du Québec.

Remaury, Bruno (2006) "Les usages culturels du mot design." In Brigitte Flamand (ed.), Le design : Essais sur des théories et des pratiques. Paris: Institut français de la mode; Éditions Regard.

Rose, Gillian (2016) Visual Methodologies: an Introduction to Researching with Visual Materials. London: Sage.

Sirois, Guillaume (2020) "Artisan or Designer: Montreal Craft Workers and the Global Discourse on Creativity." In Annette Naudin \& Karen Patel (eds), Craft Entrepreneurship. London: Rowman \& Littlefield, 89-106.

Stolarick, Kevin, Richard Florida, and Louis Musante (2005) Montréal, ville de convergences créatives: Perspective et possibilités. Montréal: Catalytix.

Straw, Will (2018) "Visibility and Conviviality in Music Scenes." In Andy Bennett and Paula Guerra (eds), DIY Cultures and Underground Music Scenes. New York: Routledge, 21-30.

Suchar, Charles S. (1997) “Grounding Visual Sociology Research in Shooting Scripts.” Qualitative Sociology, 20.1: 33-55.

Throsby, David (2010) The Economics of Cultural Policy. Cambridge: Cambridge University Press.

Tremblay, Rémy and Diane-Gabirlle Tremblay (2010) La classe créative selon Richard Florida: un paradigme urbain plausible? Québec: Presses de l'Université du Québec.

Tromp, Nynke and Paul Hekkert (2019) Designing for Society: Products and Services for a Better World. London: Bloomsbury Visual Arts.

Ville de Montréal (2006) Montréal, ville UNESCO de design (dossier de candidature). Ville de Montréal.

Vivant, Elsa and Éric Charmes (2008) "La gentrification et ses pionniers : le rôle des artistes off en question." Métropoles 3: 29-66 
Zukin, Sharon (2004) Point of Purchase: How Shopping Changed American Culture. New York: Routledge.

Zukin, Sharon (2010) Naked City: The Death and Life of Authentic Urban Places. Oxford: Oxford University Press.

\section{About the Author}

Guillaume Sirois is an assistant professor in the Department of Sociology, Université de Montréal. His current research focuses on contemporary art and other visual practices, including design, architecture, and fashion. His research interests also include cultural policy, creativity, and globalization. 